Article

\title{
Reduction of the Adhesive Friction of Elastomers through Laser Texturing of Injection Molds
}

\author{
Joel Voyer * (D), Florian Ausserer, Stefan Klien, Igor Velkavrh and Alexander Diem \\ V-Research GmbH, Stadtstrasse 33, 6850 Dornbirn, Austria; florian.ausserer@v-research.at (F.A.); \\ stefan.klien@v-research.at (S.K.); igor.velkavrh@v-research.at (I.V.); alexander.diem@v-research.at (A.D.) \\ * Correspondence: joel.voyer@v-research.at; Tel.: +43-05572-3941-5936
}

Received: 16 October 2017; Accepted: 14 November 2017; Published: 16 November 2017

\begin{abstract}
It is well known that elastomers usually possess poor dry sliding friction properties due to their highly adhesive character. In order to overcome this problematic behavior in industrial applications, interfacial materials such as oils, greases, coatings, or lacks are normally used in order to separate or to functionalize the contact surfaces of elastomers. Alternatively, the high adhesion tendency of elastomers may be explicitly reduced by modifying the elastomer composition itself or by enabling a reduction of its effective contact area through, for example, surface laser texturing. This second approach, i.e., the reduction of the adhesive character of elastomers through laser structuring, will be the main topic of the present study. For this purpose, different micro-sized grooved structures were produced on flat injection molds using an ultra-short pulsed laser. The micro-structured molds were then used to produce injection molded micro-ridged Liquid Silicone Rubber (LSR) sample pads. The investigations consisted firstly of determining the degree of replication of the mold micro-structures onto the surface of the LSR pads and secondly, to ascertain the degree of reduction of the friction force (or coefficient of friction) of these micro-ridged LSR pads in comparison to the benchmark (unstructured LSR pads) when tested under dry conditions against Aluminum alloy (Al-6082) or PA6.6-GF30 plates. For this second part of the investigation, the normal force (or contact pressure) dependency of the coefficient of friction was determined through stepwise load increasing friction tests. The results of these investigations have shown that the production of micro-ridged surfaces on LSR pads through laser structuring of the injection molds could be successfully achieved and that it enables a significant reduction of the friction force for low normal forces (or contact pressures), where the component of adhesion friction is playing an important and determining role in the overall friction behavior of the LSR elastomer.
\end{abstract}

Keywords: laser texturing; surface structuring; micro-ridges; micro-grooves; adhesion; friction; tribological characterization; liquid silicone rubber (LSR); elastomer; injection molding

\section{Introduction}

Tribo-systems using elastomeric sliding partners usually show characteristic properties in their friction and wear behaviors due primarily to their specific mechanical and superficial properties and this could be extensively explained for instance, through the basic concept of elastomer tribology, which is based on four mutually influencing friction force components, as previously described in the rubber friction theory elaborated by Kummer and Mayer [1] and Geyer [2]:

$$
F_{\text {Total }}=F_{\text {Adhesion }}+F_{\text {Hysteresis }}+F_{\text {Viscosity }}+F_{\text {Cohesion }}
$$

where the different enumerated friction force components of the total friction force $\left(F_{\text {Total }}\right)$ may be described as follow: 
- $\quad F_{\text {Adhesion: }}$ product of the effective shear stresses and the effective contact surface

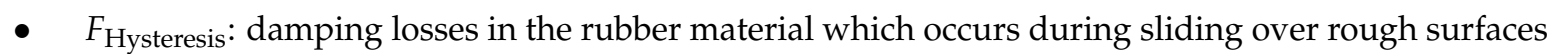
due to constantly changing deformations of elastomer

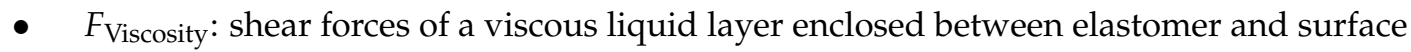

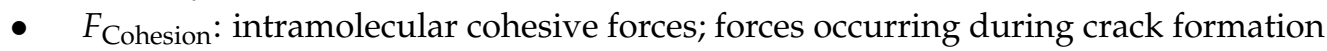

For elastomer tribo-systems without any lubrication (dry tribo-contacts), the adhesion and hysteresis components of the friction force are omnipresent and represent the significant contribution to friction; both of these components are schematically represented in Figure 1. Out of these two friction components, the adhesive friction component is generally dominant and is at its lowest for high roughness values: rougher surfaces possess a smaller effective contact area and therefore, the dominant character of adhesion is accordingly reduced. The extent of the adhesion component of the friction force is strongly dependent on the materials used. The friction coefficient of an elastomeric tribo-pairing is also dependent on the normal load and on the sliding speed.

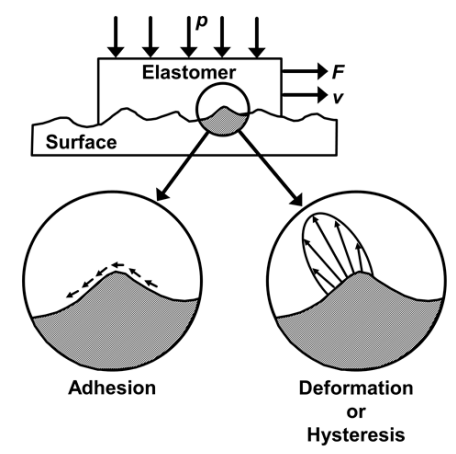

Figure 1. Schematic representations of both adhesive and deformative components of friction force for a rubber element in motion on a rough surface, adapted from [3].

Because of mutual interactions occurring in such tribo-systems, it is difficult to assign individual effects to a unique and clear dependence on load or speed. Accordingly, a high diversity of dependencies of the friction coefficient has been observed or described in numerous previously published studies [4].

In industrial applications using elastomers, several possibilities already exist for minimizing the significant contribution of their adhesive friction component. A first possibility resides in the modification of the elastomer composition itself by adding additives, which are especially optimized to reduce friction forces. A second possibility is by using intermediate materials at the interface of the contacting bodies, such as oils, greases, lacquers, or coatings, just to name a few, in order to separate the contact surfaces and reduce the elastomer's affinity to adhesive friction. A last possibility of reducing the adhesion tendency of elastomers resides in the reduction of their effective contact area through an optimized and targeted surface structuring, which represents the focus of the present manuscript. In the literature, several studies were aimed at the reduction of friction and wear of materials through the production of surface structures, but these studies were mostly focused for oil-lubricated systems, in which the surface structures acts as lubricants reservoirs, as micro-pressure chambers or as traps for wear debris [5-30]. Furthermore, as pointed out by a recent and thorough review article on the assessment of surface structuring for friction and wear improvement [31], many conflicting reports still exist concerning the effectiveness of surface texturing under certain contact conditions. However, the effect of laser surface structuring on the friction and wear behaviors in dry (unlubricated) tribo-contacts, especially for elastomers, was not thoroughly investigated in the scientific community and the present study is currently aimed at partially shedding light on this topic.

For the present study, different micro-sized grooved structures were produced on flat injection molds using an ultra-short pulsed laser. The micro-structured molds were then used to produce 
injection molded micro-ridged Liquid Silicone Rubber (LSR) sample pads. The investigations consisted firstly of determining the degree of replication of the mold micro-structures onto the surface of the LSR pads and secondly, to ascertain the degree of reduction of the friction force (or friction coefficient) of micro-ridged LSR pads in comparison to a benchmark (unstructured LSR pads) when tested under dry conditions against Aluminum or PA6.6-GF30 plates. For this purpose, the normal force (or contact pressure) dependency of the friction coefficient of unstructured (benchmark) and structured LSR elastomer was determined using stepwise load increasing friction tests.

\section{Materials and Methods}

For the fabrication of the micro-ridged elastomer LSR pads necessary for the actual study, distinctive materials and diverse methods were used at different production steps and the present section will be focused on their descriptions. For clarity purposes, the types of structures produced on the injection molds will be denominated as (micro-) grooves and the corresponding types replicated on LSR pads will be denominated as (micro-) ridges throughout the whole manuscript.

\subsection{Geometry of Surface Structures}

In previously performed internal pre-investigations, a multitude of elastomer surface structures having unidirectional micro-ridged geometries with different structure properties (width, depth, and period, just to name a few) were produced using an ultra-short pulsed laser and investigated for their friction behavior in dry contact conditions. Therefore, in order to maintain the actual manuscript as comprehensible and concise as possible, two structures showing the most promising results in terms of friction behavior were chosen from these pre-investigations, tested and reported in the present paper. For both chosen structures, representative schematics and geometrical characteristics are presented in Figure 2 and listed in Table 1, respectively. Both structures possess micro-grooves (injection mold) or micro-ridges (elastomer) having a width of $50 \mu \mathrm{m}$ and a structure period of $250 \mu \mathrm{m}$, resulting in an equivalent total reduction of the effective contact area for both structures. Only the depth of micro-grooves or micro-ridges was different for each structure: $50 \mu \mathrm{m}$ for structure 1 and $25 \mu \mathrm{m}$ for structure 2. The choice of the 2 studied structures, which possess equivalent reductions of the effective contact area but different depths was based on 2 different goals: (i) to investigate the effect of a reduction in the effective contact area of elastomers on the adhesion component of their friction force through a comparison between structured and unstructured (benchmark) elastomers; and (ii) to investigate any possible influence of the structure depth on the overall friction behavior of structured elastomers. The angle $\alpha\left(\sim 90^{\circ}\right)$ shown in Figure 2 may be roughly (but not so easily) controlled during the laser processing of the injection molds, but at this early stage of this study, it was not modified nor further optimized. However in a near future, it is intended to look at the influence of this groove (or ridge) angle on the release properties and on the overall tribological properties of injection molded structured elastomer (LSR) pads.

Table 1. Characteristics of both desired structures to be produced on injection molds through laser structuring and to be replicated on the surface of LSR pads.

\begin{tabular}{cccc}
\hline Structure & Mold Micro-Grooves/LSR Micro-Ridges & Value & Unit \\
\hline \multirow{2}{*}{1} & width & 50 & $\mu \mathrm{m}$ \\
& depth & 50 & $\mu \mathrm{m}$ \\
& period & 250 & $\mu \mathrm{m}$ \\
\hline \multirow{2}{*}{2} & width & 50 & $\mu \mathrm{m}$ \\
& depth & 25 & $\mu \mathrm{m}$ \\
& period & 250 & $\mu \mathrm{m}$ \\
\hline
\end{tabular}




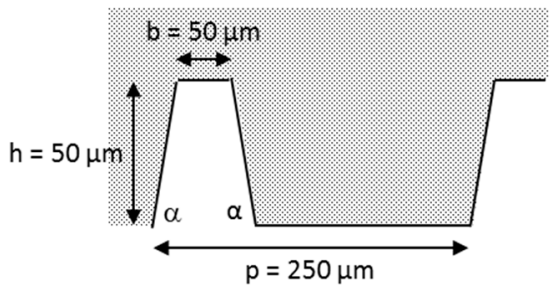

(a)

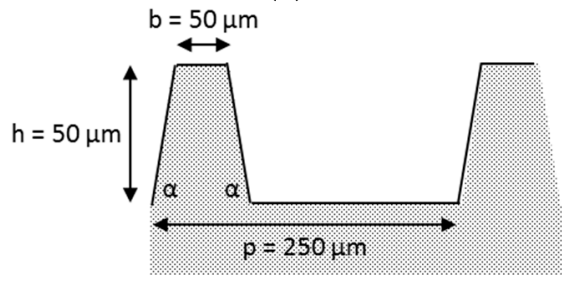

(c)

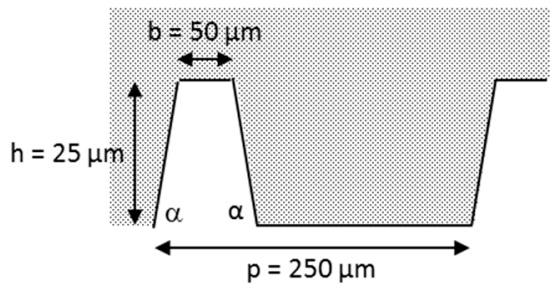

(b)

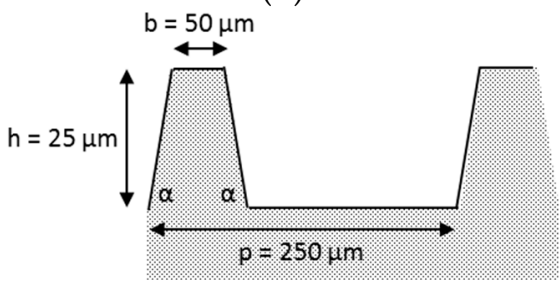

(d)

Figure 2. Side schematics of the geometries of the negative micro-grooved structures to be produced on injection molds: (a) structure 1; (b) structure 2; and the resulting micro-ridged surface structures to be produced on Liquid Silicone Rubber (LSR): (c) structure 1; (d) structure 2 (only 1 period shown in each schematic).

In order to estimate the extent of the reduction of the effective contact area of structured LSR pads, several simple calculations were performed. All formulas used for the calculation of these effective contact areas and the corresponding results are listed in Table 2. First of all, the effective contact area of the benchmark samples (unstructured LSR pads) was calculated simply as the total area of the LSR pads. For the micro-ridged LSR pads, the effective contact area was determined by firstly calculating the number of micro-ridges present along the width of the pads and secondly by multiplying this number of micro-ridges by the area of 1 micro-ridge. From Table 2, one may observe that the overall effective contact area may be reduced by a factor of approximately 5 when LSR pad surfaces possess a micro-ridged structure having a ridge width of $50 \mu \mathrm{m}$. Since both studied structures possess the same micro-ridge width, the reduction in the effective contact area is the same for both investigated surface structures. In fact, the overall reduction of the effective contact area in comparison to the benchmark (unstructured LSR pad) is exclusively influenced by both micro-ridge width and structure period:

$$
A_{\text {structured }} / A_{\text {unstructured }}=\text { micro-ridge width } / \text { structure period }
$$

Therefore, any desired modifications of the effective contact area of structured elastomer pads in comparison to benchmark pads may be performed by changing either the micro-ridge width or the structure period or both of them.

Table 2. Formulas used for the calculation of the effective contact area of unstructured (benchmark) and structured LSR pads and the corresponding results.

\begin{tabular}{ccccc}
\hline Parameter & Formula (Definition) & Formula (Values) & Result & Unit \\
\hline total area unstructured pad & pad width $\times$ pad length & $10.2 \mathrm{~mm} \times 14.5 \mathrm{~mm}$ & 147.9 & $\mathrm{~mm}^{2}$ \\
area of 1 micro-ridge & ridge width $\times$ pad length & $50 \mu \mathrm{m} \times 14.5 \mathrm{~mm}$ & 0.725 & $\mathrm{~mm}^{2}$ \\
\# of micro-ridges on pad & pad width/structure period & $10.2 \mathrm{~mm} / 250 \mu \mathrm{m}$ & 40.8 & - \\
total structured area on pad & area of 1 ridge $\times$ \# of ridges & $0.725 \mathrm{~mm}^{2} \times 40.8$ & 29.6 & $\mathrm{~mm}^{2}$ \\
ratio of structured area & $A_{\text {structured }} / A_{\text {unstructured }}$ & $29.6 \mathrm{~mm}^{2} / 147.9 \mathrm{~mm}^{2}$ & 20 & $\%$ \\
\hline
\end{tabular}




\subsection{Production and Topographical Characterization of Micro-Grooved Injection Molds}

As mentioned earlier, pre-investigations using different surface structures were used as basis for the present manuscript. Part of these pre-investigations was focused on the production of surface structures directly on the presently studied elastomer and showed also promising results. However, it is believed that modifications of the (mechanical) properties of the elastomers through the interaction of the laser with the elastomers themselves may eventually have taken place. Thus, it was not possible to distinguish if the reduction of the friction is due to the surface structures or if it was due to any modifications of elastomer properties or both. Therefore, in order to eliminate any possible modifications of elastomer properties and their eventual effect on friction, it was decided to produce the studied structures on the injections molds and thus, only the effect of the structures on the friction behavior may be individually and correctly investigated.

The laboratory-sized injection molds used in the present study had relatively small dimensions and consisted of 4 separate components: an upper casing, a lower casing, an upper plate (not shown in Figure 3 for clarity purposes, but is placed on top of the upper casing prior to the injection molding process) and an interchangeable lower steel plate as shown in Figure 3, in the opened and closed state. The upper and lower mold casings were made of Aluminum while the upper plate and the interchangeable to be structured plate were made of 1.4301 steel (EHG Stahlzentrum GmbH \& CO OG, Dornbirn, Austria). The upper mold casing possesses 5 apertures having dimension of $10.2 \mathrm{by} 14.5 \mathrm{~mm}$ (as shown in Figure 3) through which the necessary elastomer pads were injection molded and thus, the external dimensions of the pads were similar to the apertures. By using these molds, 5 elastomer pads having similar surface characteristics could be simultaneously produced. The surface roughness of the resulting elastomer pads are determined by the surface roughness of the upper and lower structured plates used. The same upper plate was used for the production of elastomer pads (structured as well as unstructured pads) and was placed on the upper casing having the apertures prior to the injection molding process. This upper plate had a surface roughness of $R_{\mathrm{a}}=2.8 \mu \mathrm{m}$ and $R_{\mathrm{z}}=14.0 \mu \mathrm{m}$, but actually did not play any role in the present study since this side of the produced pads were not tribologically characterized. For the lower plates, 3 plates were produced ( 2 for both micro-grooved structures and 1 for the benchmark) and all had a surface roughness of approximately $R_{\mathrm{a}}=0.8 \mu \mathrm{m}$ and $R_{\mathrm{z}}=5.2 \mu \mathrm{m}$. The lower plate was changed between each injection molding production run in order to obtain elastomer pads with both desired micro-ridged geometries described earlier and also for the production of benchmark pads. For the latter, the unstructured lower plate was used as is.

The previously described surface micro-structures were generated on two lower plates (1.4301 steel) using an ultra-short pulsed laser (Model femtoREGEN, High Q Laser GmbH, Rankweil, Austria) having a wavelength of $1035 \mathrm{~nm}$ and a total pulse duration of $300 \mathrm{fs}$. For the production of the studied structures, specific laser properties values were used: a laser power of $600 \mathrm{~mW}$, a pulse repetition rate of $100 \mathrm{kHz}$, a scanning speed of $50 \mathrm{~mm} / \mathrm{s}$, a pulse overlap of $95 \%$ and a laser focus spot size of about 40 to $50 \mu \mathrm{m}$. Additional properties of the laser used in the present study were previously published elsewhere [29,30].

Only 5 distinctive portions of both lower plates were actually structured. These small structured areas have dimensions slightly larger than the foreseen apertures and were centered with the corresponding location of the apertures in the upper casing of the injection molds. The structured area dimensions were chosen to be 14 by $18 \mathrm{~mm}$ (as mentioned earlier: slightly larger than the apertures for the pads) in order to avoid the possibility of having unstructured areas on the pad surfaces in case that the apertures and the small structured areas were not exactly centered together (as shown in Figure 4). 


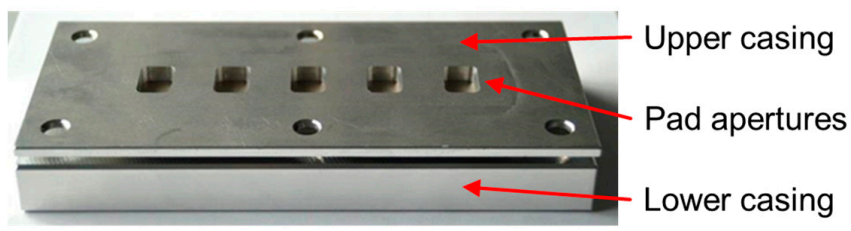

(a)

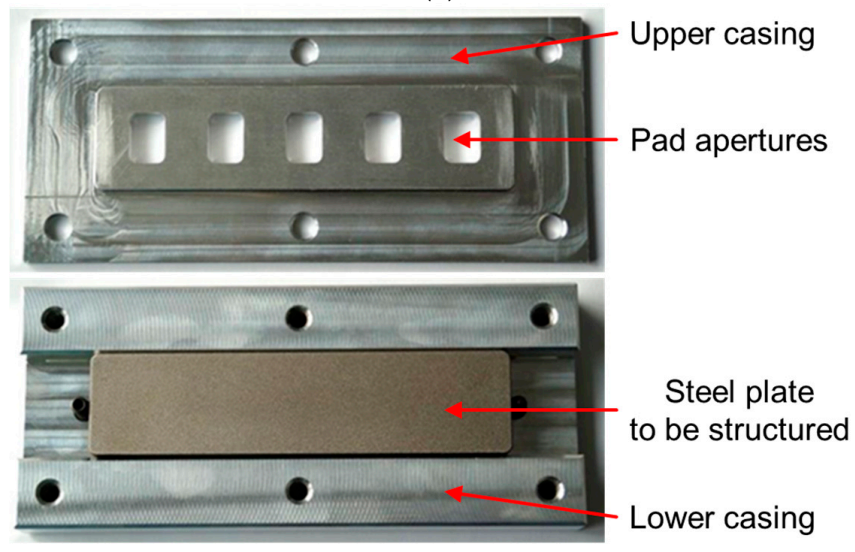

(b)

Figure 3. Injection mold used for the production of micro-ridged structures on elastomer LSR pads: (a) shown in its closed state (without the upper steel plate which is placed on top of the mold during the injection molding process); (b) in its opened state where its different components may be seen.

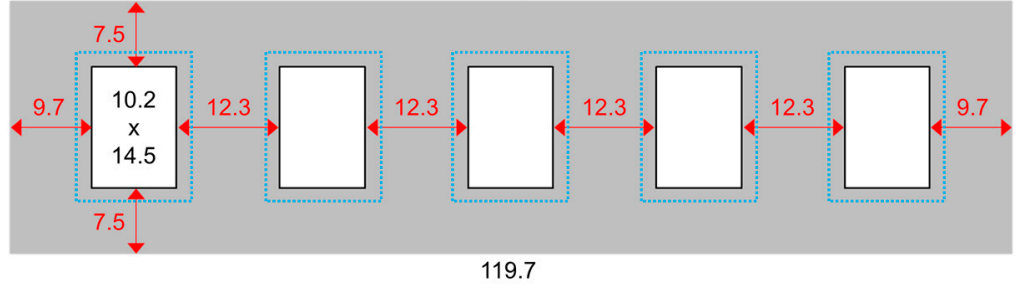

Figure 4. Position and dimensions of the upper casing apertures projected on the lower steel plate (apertures shown in white and theirs borders as black lines) along with position and dimensions of the 5 small sections to be structured on the lower steel plate (shown as dashed blue lines).

The micro-structure dimensions (width and depth of the micro-grooves and structure period) of both structured lower plates were characterized using a 3D noncontact optical surface roughness apparatus ( $\mu$ Surf, NanoFocus AG, Oberhausen, Germany). For each small structured section, 2 measurements were performed at different locations, resulting in a total of 10 measurements for each structured lower plate (5 structured sections per plate) and the average of each measured structure dimensions was reported.

\subsection{Production and Topographical Characterization of Micro-Ridged LSR Pads}

The unstructured lower plate serving as benchmark along with both structured lower plates described in the previous section were used for the production of corresponding unstructured und structured elastomer pads. Liquid Silicone Rubber (LSR) was chosen as elastomer to be used and characterized in the present study because of its exceptional thermal, mechanical and chemical resistance properties and its easiness to being processed by injection molding. Furthermore, it was chosen because LSR-based components are nowadays widely used in diverse industrials applications, such as in the automobile industry, food industry, end-consumer products or medical applications. An excerpt of the most interesting properties of LSR elastomer is listed in Table 3. 
Table 3. Excerpt of significant properties of LSR used for the production of structured pads [32].

\begin{tabular}{ccc}
\hline Property & Value & Unit \\
\hline density & 1.11 & $\mathrm{~g} / \mathrm{cm}^{3}$ \\
viscosity (shear rate $\left.0.9 \mathrm{~s}^{-1}\right)$ & $1 \times 10^{6}$ & $\mathrm{mPa} . \mathrm{s}$ \\
hardness & 60 & Shore A \\
tensile strength & 5.4 & $\mathrm{~N} / \mathrm{mm}^{2}$ \\
elongation at break & 250 & $\%$ \\
tear strength & 14 & $\mathrm{~N} / \mathrm{mm}$ \\
compression set $\left(22 \mathrm{~h} / 175^{\circ} \mathrm{C}\right)$ & 7 & $\%$ \\
\hline
\end{tabular}

The production of the LSR pads needed for the present investigations was undertaken by a third-party company and was done using standard industrial molding procedures and parameters. While the focus of the present study is mainly the evaluation of a possible reduction of the coefficient of friction of elastomer under dry conditions through a reduction of the effective contact area by using laser surface texturing, a description of the exact procedures and parameters used for the production of the desired structured LSR pads is considered to be beyond the scope of the present manuscript. Furthermore, an extensive study on an eventual optimization of the injection molding parameters was not performed for the present study, even though their influences on the overall friction behavior of LSR could be significant. Nevertheless, such an optimization process is planned to be eventually part of a future study.

The structure dimensions (width and depth of the micro-ridges and structure period) of the structured LSR pads were characterized using the same noncontact optical surface roughness apparatus along with the same procedure as the ones used for the micro-structured injection molds.

\subsection{Evaluation of the Friction Coefficient using Stepwise Load Increasing Friction Tests}

In order to evaluate the influence of a reduction of the effective contact area of elastomers through laser texturing on their friction behavior, stepwise load increasing friction tests were performed using a RVM-tribometer (RVM1000, Werner Stehr Tribologie, Horb-Ahldorf, Germany). A LSR pad was used as upper specimen and the lower specimen was either an Al-6082 (denominated as $\mathrm{Al}$ throughout the rest of the manuscript; Alcan Technology \& Management AG, Neuhausen, Switzerland) or a PA6.6-GF30 plate (denominated as PA throughout the rest of the manuscript; faigle Industrieplast $\mathrm{GmbH}$, Hard, Austria), having dimensions of about 20 by $25 \mathrm{~mm}$ and a thickness of $3 \mathrm{~mm}(\mathrm{Al})$ or $6 \mathrm{~mm}(\mathrm{PA})$ and roughness values of approximately $R_{\mathrm{a}}=0.5 \mu \mathrm{m}$ and $R_{\mathrm{z}}=3.0 \mu \mathrm{m}$ for both plate materials. The LSR pad was placed in a special sample holder, which enabled an adequate 2D-alignment of its contact surface with the surface of the underlying plate, the latter being fixed to the tribometer. The LSR pad was pressed against the chosen plate with the first pre-determined load value and moved in a linear movement at pre-determined speed and distance. In order to allow time for the pads to relax themselves and to be fully in contact with the counter plate (Al or PA), the pad was set in movement only $2 \mathrm{~s}$ after the normal force was applied. The test was then repeated for the second pre-determined load value and further on, thus the name of stepwise load increasing friction tests. For each normal force value, only 1 friction test was performed, therefore, no statistical evaluation of the obtained friction results may be performed. This whole testing was performed for both micro-structures and also for the benchmark against both plates ( $\mathrm{Al}$ or PA). The parameters used for all friction tests are summarized in Table 4 and Figure 5 shows a detailed view of the setup. 
Table 4. Parameters used for the stepwise load increasing friction tests.

\begin{tabular}{ccc}
\hline Parameter & Value & Unit \\
\hline pad material & Liquid Silicone Rubber (LSR) & - \\
plate material & Al-6082/PA6.6-GF30 & - \\
normal forces & $10,15,20,25,30,40,50,80,100,200,400,600$ & $\mathrm{~N}$ \\
speed & 48 & $\mathrm{~mm} / \mathrm{min}$ \\
displacement & 11 & $\mathrm{~mm}$ \\
temperature & 22 & ${ }^{\circ} \mathrm{C}$ \\
lubrication & none (dry) & - \\
\hline
\end{tabular}

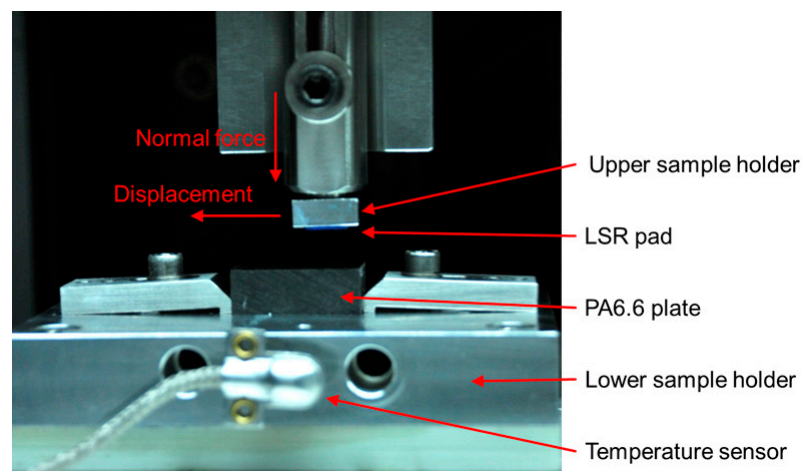

Figure 5. Photograph detailing the test setup used for performing the stepwise load increasing friction tests on the RVM-tribometer.

During the whole duration of stepwise load increasing friction tests, time, normal force, friction force, friction coefficient, speed, position and temperature were controlled and monitored through the software of the RVM-tribometer and saved accordingly in separate files for subsequent analysis. A detailed description of this post-analysis is described in Section 3.3 using a measurement example.

At the present stage of the study, the overall wear resistance of the studied surface micro-structures on LSR was not yet investigated, since at first, it was intended to determine if such surface structuring, and to another extent which structures had any significant effects on the friction behavior. However, investigations on the wear resistance or durability of the studied micro-ridged elastomer surface structures are planned to be performed and published subsequently.

\section{Results and Discussion}

The presentation of the different results obtained from the various characterization steps performed in the actual study will be divided accordingly to the previous section in order to maintain the overall manuscript as concise and clear as possible.

\subsection{Topographical Characterization of Micro-Grooved Injection Molds}

An overview of both micro-grooved injection molds are shown in Figure 6. As mentioned earlier, it is easily observed that only 5 small regions are structured on each mold plate and these regions correspond exactly to the locations of the apertures in the top plate of the mold. A more detailed analysis of the micro-grooved structures was performed in order to ascertain the accordance of the dimensions of produced micro-grooves with their initial desired dimensions.

A detailed topographical analysis of both micro-grooved structures produced on injection molds is shown in Figure 7. The measurements of the dimensions of the micro-structures have shown that the micro-grooved structures produced on the injection molds using the ultra-short pulse laser possess the initial desired dimensions, as listed in Table 5. These results show that the production of micro-grooved structures on the surface of injection molds made of steel 1.4301 can be accurately manufactured. 
However, the attainment of structures possessing the desired dimensions is not a one-shot process; optimization steps are previously necessary for any new material in order to adjust the different laser parameters in order to obtain the width and depth of the desired structures. Therefore, the actual optimized laser parameters found for molds made of steel 1.4301 used in the present study may not be used for molds made from any other steels.

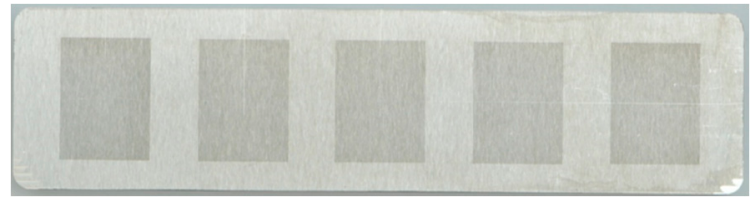

(a)

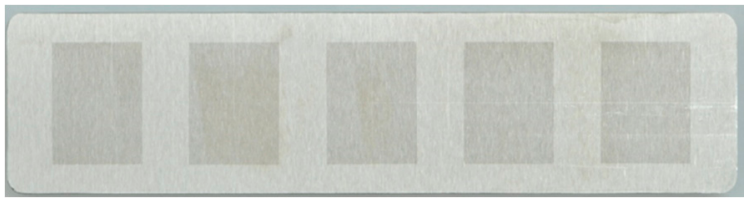

(b)

Figure 6. Overview photographs of both injection molds having 5 small regions with the desired micro-grooved structures: (a) structure 1 ; (b) structure 2.

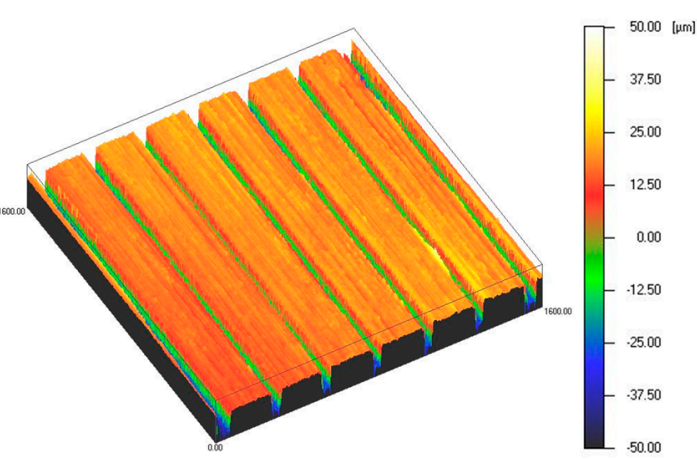

(a)

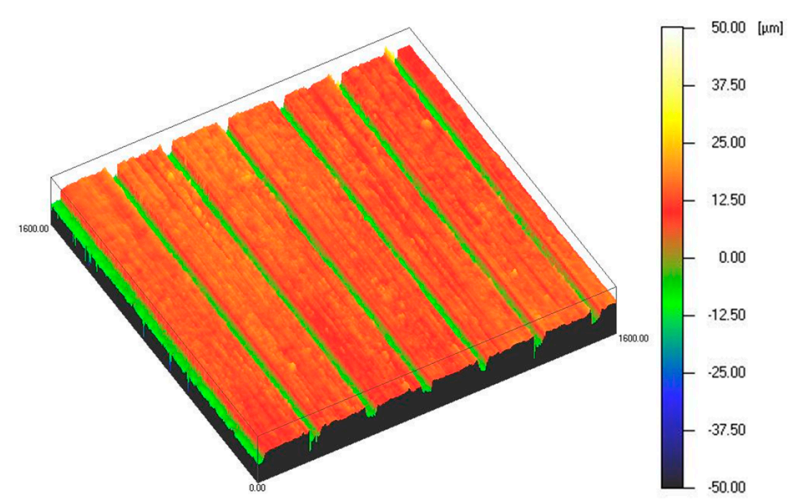

(b)

Figure 7. Typical topographies of micro-grooved injection molds: (a) structure 1; (b) structure 2.

Table 5. Dimensions of micro-grooved structures produced on injection molds using an ultra-short pulsed laser and surface roughness values of injection mold used for the benchmark LSR pads.

\begin{tabular}{ccccc}
\hline Structure & Dimension & Target Value & Actual Value & Unit \\
\hline \multirow{3}{*}{ structure 1 } & micro-groove width & 50 & 48.1 & $\mu \mathrm{m}$ \\
& micro-groove depth & 50 & 49.6 & $\mu \mathrm{m}$ \\
& structure period & 250 & 248.8 & $\mu \mathrm{m}$ \\
& $A_{\text {structured }} / A_{\text {unstructured }}$ & 20 & 19.3 & $\%$ \\
\hline \multirow{5}{*}{ structure 2 } & micro-groove width & 50 & 49.6 & $\mu \mathrm{m}$ \\
& micro-groove depth & 25 & 23.0 & $\mu \mathrm{m}$ \\
& structure period & 250 & 248.6 & $\mu \mathrm{m}$ \\
\hline \multirow{2}{*}{ benchmark } & $A_{\text {structured }} / A_{\text {unstructured }}$ & 20 & 20 & $\%$ \\
& $R_{\mathrm{a}}$ & 0.8 & 0.8 & $\mu \mathrm{m}$ \\
& $R_{\mathrm{z}}$ & 5.2 & 5.2 & $\mu \mathrm{m}$ \\
\hline
\end{tabular}

\subsection{Topographical Characterization of Micro-Ridged LSR Pads}

As already described earlier, the micro-grooved injection molds were used for the production of micro-structured LSR pads, with the aim of obtaining a high replication of the micro-structures from the molds onto the elastomer pads. A small vertical line was observed in the middle of both pads and was actually a replicate of a tiny orientation line marked at the center of the molds to be structured which served as a guideline during the laser processing. The influence of this centerline on the friction 
behavior of the LSR pads is thought to be minimal since its depth is significantly smaller than the depth of the produced micro-ridged structures. The replication degree of the micro-grooves onto the LSR pads was determined by measuring the micro-ridges dimensions using the aforementioned 3D noncontact optical surface roughness apparatus.

A detailed topographical analysis of both micro-ridged structures produced on LSR pads is shown in Figure 8. First of all for structure 1, it was observed that 2 LSR pads (out of 5 pads) had some surface areas with defects, i.e., the micro-ridges were not properly fabricated. It was observed that micro-ridges were either not present or did not have the desired geometry or dimensions. A typical surface topography of such regions having surface structure defects for structure 1 is shown in Figure 8a. At this stage of the present study, it is not yet known if these problematic surface areas are due to the fact that LSR did not fill properly some micro-grooves of the injection mold due to the higher depth value of $50 \mu \mathrm{m}$ or if the micro-ridges on the surface of LSR pads were torn apart from the pad surface during the unmolding step. However, quick visual observations of the surfaces of the injection mold after the injection process did not reveal any traces of LSR trapped in the micro-grooves of the mold. Therefore, based on these visual observations, it is believed that the presence of defect zones on some LSR pads with structure 1 may be due to the fact that a micro-groove depth of $50 \mu \mathrm{m}$ was probably on the edge of being too deep for the given viscosity of LSR, which impaired a complete filling of the mold's micro-grooves during the injection molding process. However, the exact cause of these defect zones was not further analyzed, since, as mentioned previously, an optimization of the molding process is not part of the present study.

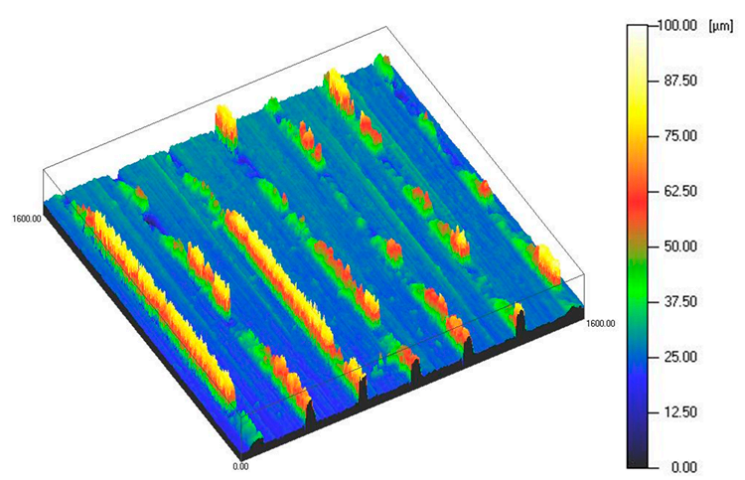

(a)

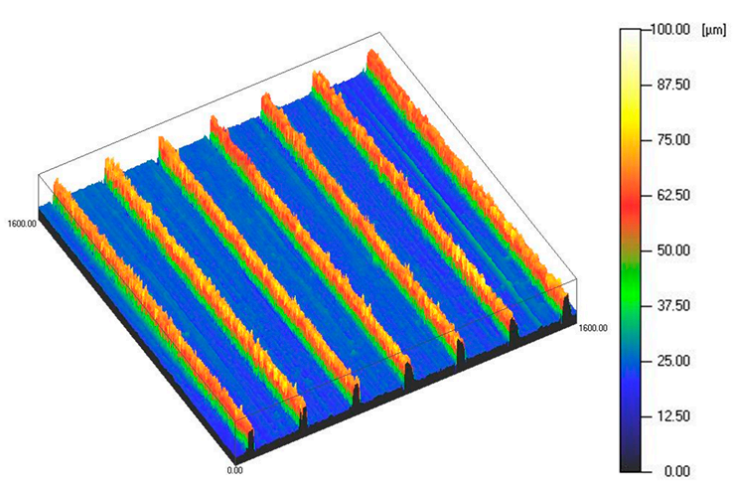

(b)

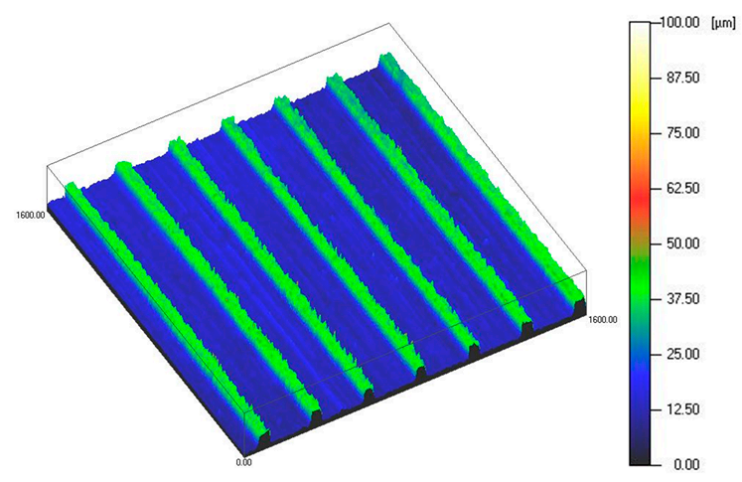

(c)

Figure 8. Typical surface topographies of injection molded micro-ridged LSR pads: (a) structure 1: problematic region with defects; (b) structure 1: defect-free region; (c) structure 2.

For all other micro-ridged LSR pads (structure 1: remaining 3 pads; structure 2: all 5 pads), they were all perfectly replicated from the injection molds and had only defect-free micro-structured surfaces, as shown in Figure 8b,c. Furthermore, Table 6 lists results of the measurements of the 
structure dimensions on LSR pads. A comparison of these results with results obtained from the injection molds (Table 5) shows that the degree of replication of micro-grooved structures from laser-structured injection molds onto LSR pads is relatively high, in which one may observe that the obtained structure dimensions are almost equal to the desired dimensions. From these results obtained from the characterization of the micro-ridged LSR pads, it is clear that the production of defect-free pads having the desired dimensions using laser-structured injection molds is realizable. However, for deep structures such as structure 1 (depth of $50 \mu \mathrm{m}$ or more), the production of defect-free pads is more challenging and would need further optimization of the molding process, which is not part of the present study. Finally, it is worth noting here that for the friction evaluation (next section) of pads structured with structure 1, only defect-free LSR pads were used.

Table 6. Dimensions of micro-ridged structures produced on LSR pads using laser-structured injection molds and surface roughness values of benchmark LSR pads.

\begin{tabular}{ccccc}
\hline Structure & Dimension & Target Value & Actual Value & Unit \\
\hline \multirow{4}{*}{ structure 1 } & micro-ridge width & 50 & 41.5 & $\mu \mathrm{m}$ \\
& micro-ridge depth & 50 & 51.8 & $\mu \mathrm{m}$ \\
& structure period & 250 & 248.9 & $\mu \mathrm{m}$ \\
& $A_{\text {structured }} / A_{\text {unstructured }}$ & 20 & 16.7 & $\%$ \\
\hline \multirow{4}{*}{ structure 2 } & micro-ridge width & 50 & 52.5 & $\mu \mathrm{m}$ \\
& micro-ridge depth & 25 & 25.5 & $\mu \mathrm{m}$ \\
& structure period & 250 & 246.0 & $\mu \mathrm{m}$ \\
& $A_{\text {structured }} / A_{\text {unstructured }}$ & 20 & 21.3 & $\%$ \\
\hline \multirow{2}{*}{ benchmark } & $R_{\mathrm{a}}$ & 0.8 & 0.8 & $\mu \mathrm{m}$ \\
& $R_{\mathrm{z}}$ & 5.2 & 5.3 & $\mu \mathrm{m}$ \\
\hline
\end{tabular}

\subsection{Evaluation of the Friction Coefficient of Benchmark and Micro-Ridged LSR Pads}

For each normal load (or force) value under study, the measurements obtained from the tribometer were then plotted in a time diagram showing the normal force and the coefficient of friction during the whole test duration. A typical friction curve obtained from the RVM-tribometer is shown in Figure 9 (structure 2 against PA for a normal force of $25 \mathrm{~N}$ ), where the normal force and the coefficient of friction $(\mathrm{COF})$ as well as their averages are shown. The averages were calculated from the sliding portion of the curve, i.e., after the stiction value was reached for the benchmark and also for both micro-ridged structures against both counter plates (Al and PA) and for all applied normal forces. Additionally, exact stiction values were extracted from each curves obtained for the benchmark and also for both micro-ridged structures, again against both plates and for all applied normal forces. Furthermore, from the curve shown in Figure 9 and as mentioned earlier, it can also be observed that the movement of the pad on the counter plate starts after a pause of approximately $2 \mathrm{~s}$ in order to allow time for relaxation of the LSR pads to take place and to allow them to be fully in contact with the counter plate.

For the analysis of the effect of the micro-ridged structures on the friction behavior of LSR, the calculated COF averages and the extracted stiction values were plotted against their corresponding normal forces for the benchmark and for both micro-ridged structures for each counter plate (Al or PA). In order to keep this manuscript clear and concise, results from the sliding friction coefficient will be presented at first followed by the results from the stiction.

The sliding friction coefficient results of the stepwise load increasing friction tests for the benchmark (unstructured) and of the structured LSR pads (micro-ridged structures 1 and 2) are shown together in Figure 10a,b against $\mathrm{Al}$ and in Figure 10c,d against PA. Each point represents the calculated average of the friction coefficient (calculated from the sliding section of the obtained curve as shown in Figure 9) for the specified applied normal force. In all diagrams shown in Figure 10, trend lines (based on a power function) were added in order to help the reader to obtain a quick visual overview of the load dependency of the friction coefficient for each studied surface structures 
in comparison to the benchmark. The use of such power function trend lines has no physical reason and should not be used as a phenomenological description of the load dependency of the friction force or friction coefficient; these trend lines were chosen only to enhance the visual clarity of the diagrams shown.

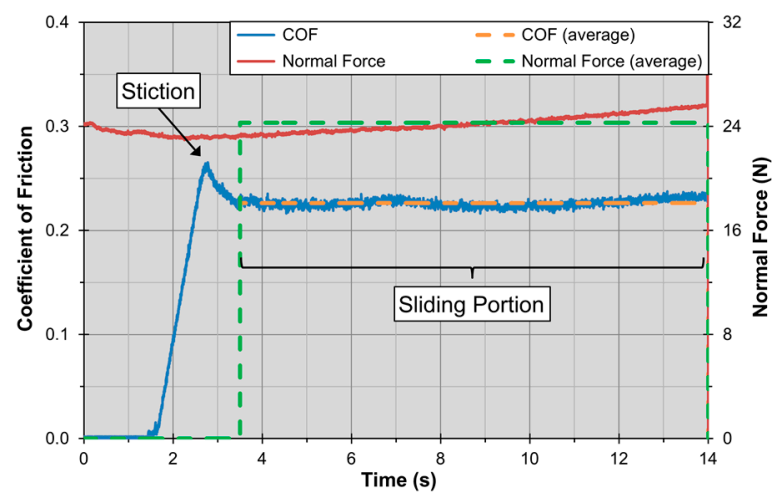

Figure 9. Typical curve showing the normal force (red) and friction coefficient (coefficient of friction (COF) blue) measured by the tribometer and the corresponding post-analysis values: average of normal force (dashed green) and average of friction coefficient (COF dashed orange) in the sliding portion of the curve along with the stiction value (curve obtained from structure 2 against PA for a normal force of $25 \mathrm{~N}$ ).

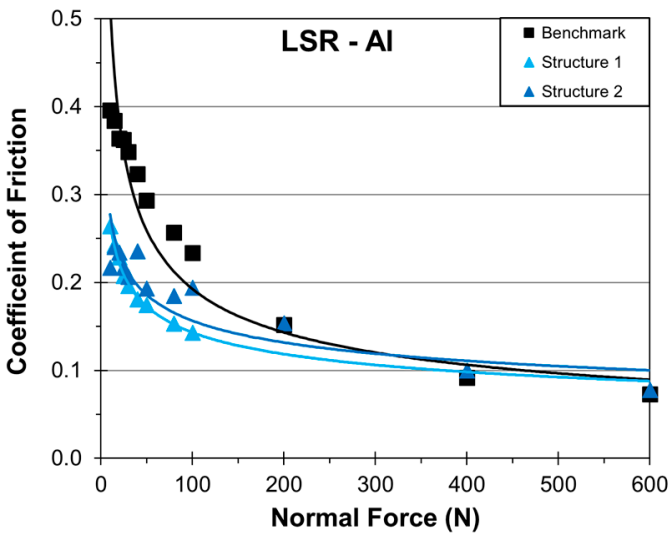

(a)

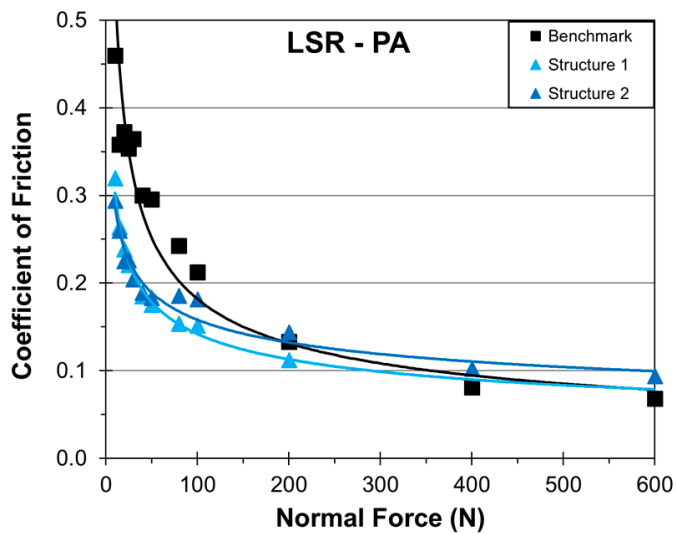

(c)

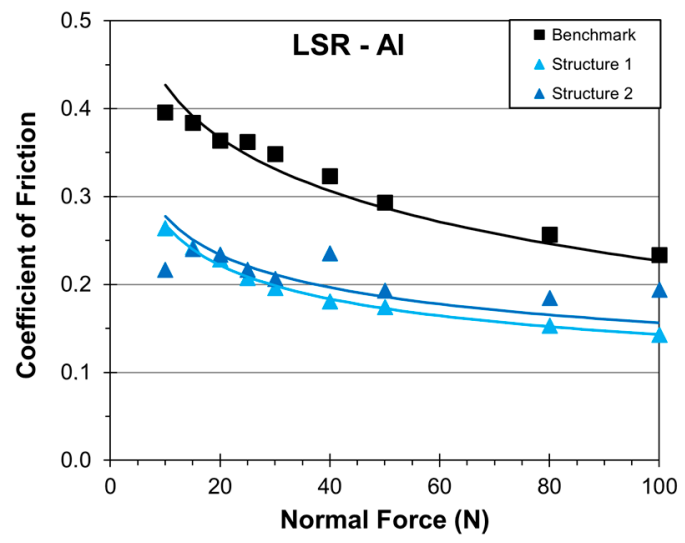

(b)

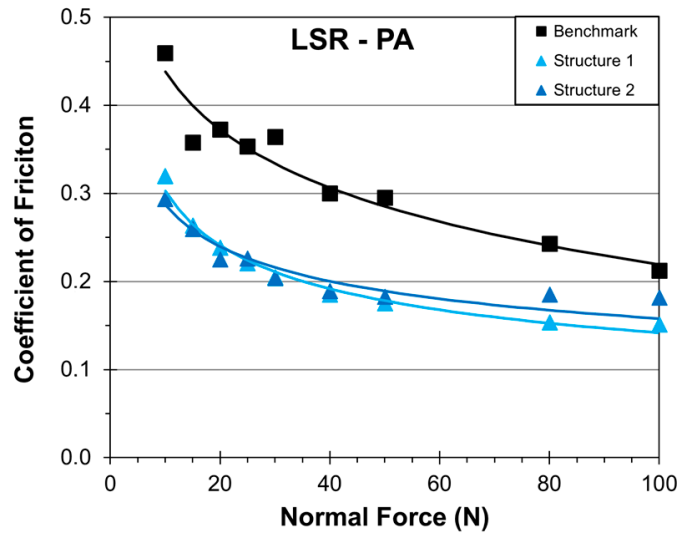

(d)

Figure 10. Averages of friction coefficients from stepwise load increasing friction tests for benchmark and micro-ridged LSR pads against $\mathrm{Al}(\mathbf{a}, \mathbf{b})$ and against PA $(\mathbf{c}, \mathbf{d})$ (trend lines shown only for visual clarity): (a) Al: total normal force range $(10-600 \mathrm{~N})$; (b) Al: low normal force range $(<100 \mathrm{~N})$; (c) PA: total normal force range $(10-600 \mathrm{~N})$; (d) PA: low normal force range $(<100 \mathrm{~N})$. 
First of all, from a general observation, it may be easily observed in Figure 10, that all curves shown (for the benchmark and also for both structures) possess similar forms; i.e., the friction coefficients increase rapidly when the normal loads are reduced towards zero and when the normal loads are increased, the friction coefficients decrease and tend to reach a constant value which is independent of the normal loads used. These observations were also observed and described in previous studies [33-35]. This dependency of the friction coefficient (or friction force) on the normal load is due to the molecular adhesion of the elastomer: the predominance of adhesion is at its highest level for low load values and decreases with increasing normal loads [33].

Furthermore, by comparing curves shown in Figure 10b for LSR against $\mathrm{Al}$ and Figure $10 \mathrm{~d}$ for LSR against PA, one may clearly see that the friction coefficients are slightly higher for the PA plate. This is caused by the fact that, even though the total surface energies of PA and $\mathrm{Al}$ from the literature are quite similar, the polar surface energy of PA is however higher than $\mathrm{Al}$, as shown in Table 7 . No values for Al-6082 or for PA6.6GF30 used in the present study were actually found in the literature but nevertheless, one may use the values listed in Table 7 as approximate values for the actual plate materials investigated and presented in the actual manuscript.

A comparison of the results obtained from structure 1 and from structure 2 shown in Figure 10 shows that the friction coefficients measured are equivalent for both structures, thus indicating that the variation of the structure depth (50 $\mu \mathrm{m}$ for structure 1 and $25 \mu \mathrm{m}$ for structure 2 ) has no significant influence on the adhesion component of the friction force.

A detailed analysis of the results from the sliding friction coefficients of LSR pads against $\mathrm{Al}$ or PA can be performed simultaneously since the results show similar tendencies. Diagrams from Figure 10a,c clearly show that the friction coefficients of both micro-structures are significantly lower than the friction coefficient of the benchmark for normal forces lower than approximately $200 \mathrm{~N}$, and that for normal forces higher than $200 \mathrm{~N}$, no reduction in the friction coefficient may be observed.

Table 7. Superficial energies of Al-alloys and PA (Owens-Wendt method; remark: $\mathrm{mJ} / \mathrm{m}^{2}=\mathrm{mN} / \mathrm{m}$ ).

\begin{tabular}{|c|c|c|c|c|}
\hline Material & Property & Value & Unit & References \\
\hline \multirow{3}{*}{ Al-2024 } & total surface energy & 38.9 & & \multirow{6}{*}[36]{} \\
\hline & polar surface energy & 2.7 & $\mathrm{~mJ} / \mathrm{m}^{2}$ & \\
\hline & dispersive surface energy & 36.2 & & \\
\hline \multirow{3}{*}{ Al-7075 } & total surface energy & 41.4 & \multirow{3}{*}{$\mathrm{mJ} / \mathrm{m}^{2}$} & \\
\hline & polar surface energy & 6.1 & & \\
\hline & dispersive surface energy & 35.3 & & \\
\hline \multirow{3}{*}{ PA6 } & total surface energy & $72.1 / 47.5$ & \multirow{3}{*}{$\mathrm{mN} / \mathrm{m}$} & \multirow{3}{*}[4,37]{} \\
\hline & polar surface energy & $38.3 / 10.7$ & & \\
\hline & dispersive surface energy & $33.8 / 36.8$ & & \\
\hline \multirow{3}{*}{ PA6.6 } & total surface energy & 63.4 & \multirow{3}{*}{$\mathrm{mJ} / \mathrm{m}^{2}$} & \multirow{3}{*}{ [4] } \\
\hline & polar surface energy & 32.8 & & \\
\hline & dispersive surface energy & 30.6 & & \\
\hline
\end{tabular}

The observation that at high loads, no reduction in the friction coefficient can be obtained is believed to be due to the fact that at these high loads, the adhesive component of the friction force is playing a secondary role, thus any reduction of the effective contact area through surface structuring has only small influences on the overall friction coefficient. Furthermore, the load bearing capability of both micro-ridged structures is relatively low, and thus at high normal forces, the micro-ridges do not possess the necessary stiffness to stay in an upright position and are prone to bend themselves under the imposed unidirectional movement, thus increasing significantly the effective contact area of the structured pads to the point of almost reaching the contact area of the benchmark pads and hence, the beneficial effect of a reduction of the effective contact area on the overall friction coefficient is lost. The present hypothesis is confirmed by a previously published work on the adhesive friction 
behaviors of elastomers, in which it was described that the fact that the friction coefficients become relatively constant for high normal loads implies that the effective contact area increases proportionally to the normal load for high loads [33].

However, at low normal forces $(<100 \mathrm{~N})$ as shown in Figure $10 \mathrm{~b}$,d, it may be seen that a reduction in the effective contact area through surface structuring in the form of micro-ridges may indeed decrease significantly the overall friction coefficient of LSR in comparison to unstructured LSR, which is due to the reduction of the adhesive friction of LSR at these low loads. In more details, for normal forces lower than approximately $40 \mathrm{~N}$, the total coefficient of friction of LSR may be decreased by a factor ranging from 1.5 to approximately 2 . However, the reduction factor in the friction coefficient decreases with increasing normal forces, i.e., the beneficial effect of a reduction of the effective contact area on the coefficient of friction of LSR is only significant for a normal load range where the dominance of the adhesive friction is at its highest, i.e., at low normal forces.

The stiction results of the stepwise load increasing friction tests for the benchmark (unstructured) and for the structured LSR pads (micro-ridged structures 1 and 2) are shown together in Figure 11a,b against $\mathrm{Al}$ and in Figure 11c,d against PA. As for diagrams showing results of the sliding friction coefficient (Figure 10), in all diagrams shown in Figure 11, trend lines (based on a power function) were added in order to help the reader to obtain a quick visual overview of the load dependency of the friction coefficient for each studied surface micro-structures in comparison to the benchmark.

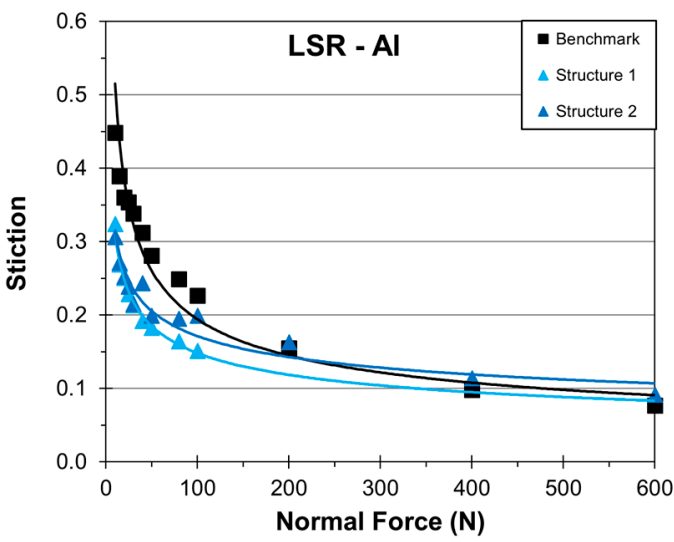

(a)

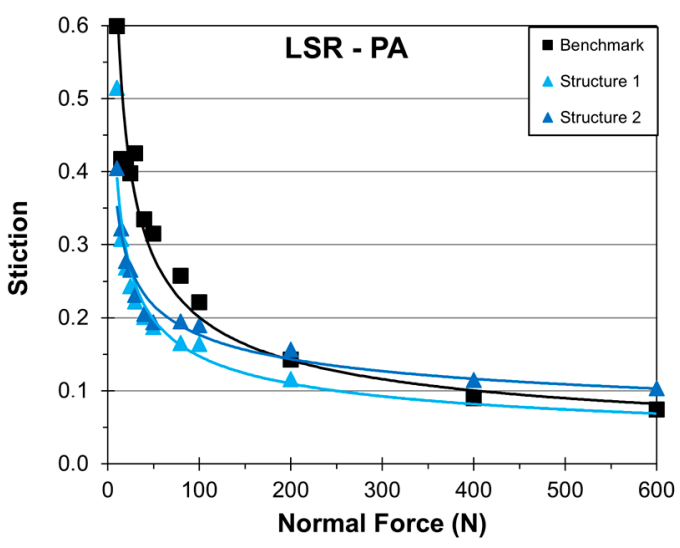

(c)

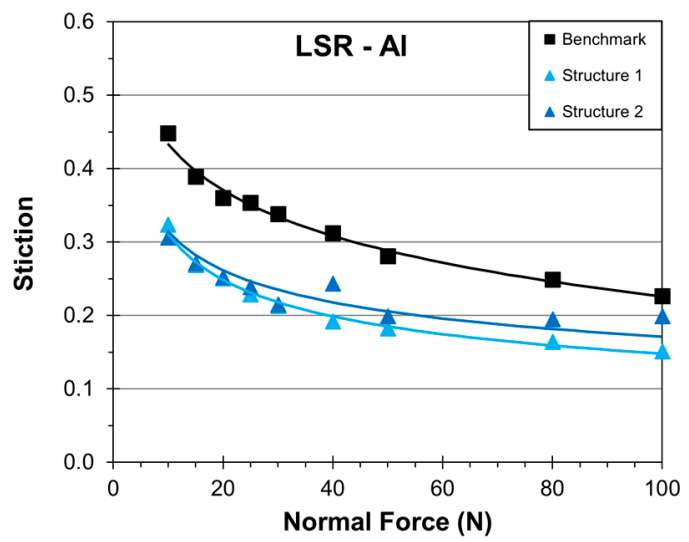

(b)

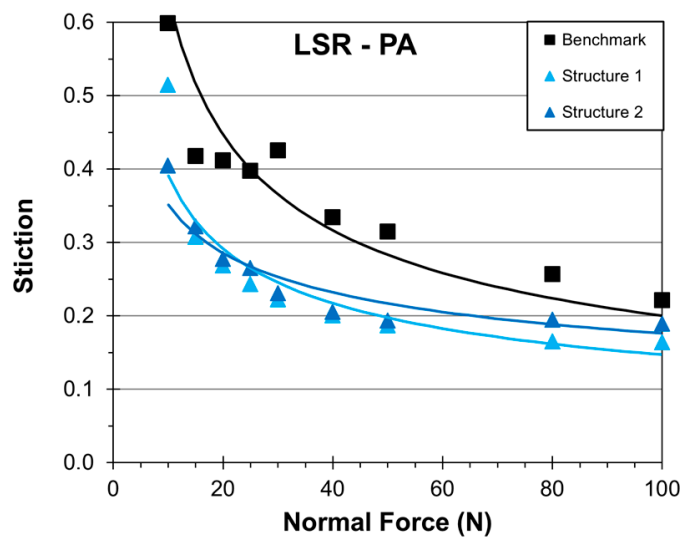

(d)

Figure 11. Stiction values obtained from stepwise load increasing friction tests for benchmark and for micro-ridged LSR pads against $\mathrm{Al}(\mathbf{a}, \mathbf{b})$ and against PA (c,d) (trend lines shown only for visual clarity): (a) Al: total normal force range $(10-600 \mathrm{~N})$; (b) Al: low normal force range $(<100 \mathrm{~N})$; (c) PA: total normal force range $(10-600 \mathrm{~N})$; (d) PA: low normal force range $(<100 \mathrm{~N})$. 
As for the friction coefficients results discussed previously, from a general observation, it may be easily observed in Figure 11, that all curves shown possess similar forms. This dependency of the friction coefficient (or friction force) on the normal load is, as previously mentioned, due to the molecular adhesion of the elastomer: the predominance of adhesion is at its highest level for low load values and decreases with increasing normal loads [33].

As for the sliding friction coefficients presented previously, one may clearly see that the stiction values are slightly higher for LSR against PA (Figure 11d) than for LSR against Al (Figure 11b). As described previously, this is caused by the fact that the polar surface energy of PA is higher than for $\mathrm{Al}$, as listed in Table 7.

Again, equivalent friction coefficients of both structures 2 (as shown in Figure 11 indicates that the variation of the structure depth $(50 \mu \mathrm{m}$ for structure 1 and $25 \mu \mathrm{m}$ for structure 2$)$ has no significant influence on the adhesion component of the friction force.

A detailed analysis of the results from the stiction values of LSR pads against Al or PA can be performed simultaneously since the results show similar tendencies. Furthermore, the results related to stiction show the same trends as the results obtained for the friction coefficients (Figure 10) and will be here only shortly described, since the influence of the reduced contact area on the stiction of micro-ridged LSR pads is similar as the one observed previously for the friction coefficients.

Diagrams from Figure 11a,c clearly show that the stiction of both structures are significantly lower than the stiction of the benchmark for normal forces lower than approximately $200 \mathrm{~N}$, and that for normal forces higher than $200 \mathrm{~N}$, no reduction in the stiction may be observed.

Again for high loads, the fact that no reduction in the stiction can be obtained is believed to be due to the fact that at these high loads, the adhesive component of the friction force is playing a secondary role, thus any reduction of the effective contact area through surface structuring has only small influences on the overall friction coefficient. Furthermore, the load bearing capability of both structures is relatively low and thus, the micro-ridges are prone to bend under the imposed unidirectional movement, thus eliminating the beneficial effect of a reduced contact area due to an increased effective contact area. And again, this hypothesis is confirmed by a previously published work on the adhesive friction behaviors of elastomers, in which it was described that the fact that the friction coefficients become relatively constant for high normal loads implies that the effective contact area increases proportionally to the normal load for high loads [33].

Again at low normal forces $(<100 \mathrm{~N})$ as shown in Figure 11b,d, a reduction in the effective contact area through surface structuring in the form of micro-ridges may indeed decrease significantly the stiction in comparison to unstructured LSR, which is due to the reduction of the adhesive friction of LSR at these low loads. Again for normal forces lower than approximately $40 \mathrm{~N}$, the stiction of LSR may be decreased by a factor ranging from 1.5 to approximately 2 . However, similar to the previous observations made for the friction coefficients, the reduction factor in the stiction decreases with increasing normal forces, i.e., the beneficial effect of a reduction of the effective contact area on the stiction of LSR is only significant for a normal load range where the dominance of the adhesive friction is at its highest, i.e., at low normal forces.

An optimization of the load carrying capability of the investigated structure geometries may represent a necessary step for an eventual deployment of such micro-structured elastomers in any industrial applications, where not only low loads but also high normal loads prevail. One possibility relies on a pin-pointed elastomer-specific optimization of the ratio between the width and the height of the micro-ridges. It is logical that narrow micro-ridges have the tendency to be more deformable than wide micro-ridges and these dimensions (and their ratio) must be specifically optimized for each elastomer to be used in any industrial application. However, this sort of structure/material optimization, which implies a major appropriation of resources, is out of scope of the present study.

Finally, as mentioned earlier, the durability or wear resistance of the present micro-ridged surface structures on LSR has not yet been studied but is planned to be part of near future investigations. 


\section{Conclusions}

The present study has shown that the production of surface structures having specific micro-sized dimensions on steel injection molds using an ultra-short pulsed lased was accurate and highly feasible. Furthermore, a high degree of reproduction of these micro-sized structures from the molds onto the surfaces of LSR pads may also be achieved. However, for the surface structure having the highest depth (structure 1 with a depth of $50 \mu \mathrm{m}$ ), the reproduction of the structure was not completely defect-free, as shown by the presence of some distorted or missing micro-ridges on several surface areas of 2 produced pads (out of 5 pads). This problematic areal reproduction of the micro-structure onto some of the LSR pads may be due to 2 different causes:

- non-optimized combination of a high micro-groove depth and LSR viscosity: i.e., the mold micro-grooves could have been partly too deep to be filled completely by the LSR elastomer

- LSR micro-ridges were damaged or torn away in some zones of the affected pads during the unmolding process due to a higher adhesion of LSR pads to the injection molds

However, no detailed investigations were performed in order to determine the exact cause of the presence of such defect zones, but based on a simple visual observation of the mold after the injection molding process, which showed that no LSR traces could be observed on the mold surface with the structure 1, it is thus believed that the combination "micro-grooves depth-LSR viscosity" could be the real cause for the presence of defect zones for structure 1 on the 2 affected LSR pads. A targeted optimization of the injection molding process (temperature, use of optimized unmolding agents, etc.) could eventually help solving this punctual structure replication problematic.

The experimental investigations have shown that, by comparing results from both structures (which exhibited equivalent friction coefficients), the variation of the structure depth $(50 \mu \mathrm{m}$ for structure 1 and $25 \mu \mathrm{m}$ for structure 2) has no significant influence on the adhesion component of the friction force. This observation was already anticipated since it is believed that only the effective contact area has a significant influence on the adhesive component of the friction force.

Furthermore, the tribological investigations have shown that at high normal loads, the micro-structured elastomer pads exhibit similar friction coefficients or stiction as the benchmark (unstructured pads). This is believed to be due to the fact that the adhesive component of the friction force is playing a secondary role at high loads, thus any reduction of the effective contact area through surface structuring has only small influences on the overall friction coefficient. Furthermore, it is also believed to be due to the low load carrying capability of the elastomer micro-ridges, which at high loads generates a buckling of the structure, which in turn induces an increase in the effective contact area of the structured pads and ultimately leads to friction behaviors similar to the benchmark.

For low normal loads (approximately lower than $40 \mathrm{~N}$ ) where the predominance of adhesion friction is at its highest, a reduction of the friction coefficient or of the stiction by a factor ranging from 1.5 to approximately 2 could be easily reached. This overall friction reduction results directly from the induced reduction of the effective contact area through laser structuring, which in turn minimizes the overall contribution of the adhesive friction component onto the total friction force.

Acknowledgments: The work presented herein was funded by the Austrian COMET Programme (Project XTribology, No. 849109) and carried out at the "Excellence Centre of Tribology" (AC ${ }^{2} \mathrm{~T}$ research GmbH) in cooperation with V-Research $\mathrm{GmbH}$.

Author Contributions: Joel Voyer, Florian Ausserer, Stefan Klien, Igor Velkavrh and Alexander Diem conceived and designed the experiments; Joel Voyer and Stefan Klien performed the experiments; Joel Voyer, Stefan Klien and Alexander Diem analyzed the data; Joel Voyer and Alexander Diem wrote the paper.

Conflicts of Interest: The authors declare no conflict of interest. The founding sponsors had no role in the design of the study; in the collection, analyses, or interpretation of data; in the writing of the manuscript, and in the decision to publish the results. 


\section{References}

1. Kummer, H.W. Unified Theory of Rubber and Tire Friction; Pennsylvania State University: University Park, PA, USA, 1966.

2. Geyer, W. Contribution to the Theory of Rubber on Dry and Especially on Wet Surfaces (In German: Beitrag zur Gummireibung auf Trockenen und Insbesondere Nassen Oberflächen). Ph.D. Thesis, Technical University Munich, Munich, Germany, 1971.

3. Moore, D.F. The Friction and Lubrication of Elastomers_-Fundamental Concepts; Pergamon Press: Oxford, UK, 1972; ISBN 978-008-016-749-7.

4. Sinha, S.K.; Briscoe, B.J. Polymer Tribology; Imperial College Press: London, UK, 2009; ISBN 978-184-816-202-0.

5. Voevodin, A.A.; Zabinski, J.S. Laser Surface Texturing for Adaptive Solid Lubrication. Wear 2006, 261, 1285-1292. [CrossRef]

6. Andersson, P.; Koskinen, J.; Varjus, S.; Gerbig, Y.; Haefke, H.; Georgiou, S.; Zhmud, B.; Buss, W. Microlubrication Effect by Laser-Textured Steel Surfaces. Wear 2007, 262, 369-379. [CrossRef]

7. Huang, W.; Wang, X. Biomimetic Design of Elastomer Surface Pattern for Friction Control under Wet Conditions. Bioinspir. Biomim. 2013, 8, 46001. [CrossRef] [PubMed]

8. Vilhena, L.M.; Podgornik, B.; Vizintin, J.; Mozina, J. Influence of Texturing Parameters and Contact Conditions on Tribological Behaviour of Laser Textured Surfaces. Meccanica 2011, 46, 567-575. [CrossRef]

9. Shinkarenko, A.; Kligerman, Y.; Etsion, I. Theoretical Analysis of Surface-Textured Elastomer Sleeve in Lubricated Rotary Sliding. Tribol. Trans. 2010, 53, 376-385. [CrossRef]

10. Shinkarenko, A.; Kligerman, Y.; Etsion, I. The Validity of Linear Elasticity in Analyzing Surface Texturing Effect for Elastohydrodynamic Lubrication. J. Tribol. 2009, 131, 021503. [CrossRef]

11. Shinkarenko, A.; Kligerman, Y.; Etsion, I. The Effect of Elastomer Surface Texturing in Soft Elasto-Hydrodynamic Lubrication. Tribol. Lett. 2009, 36, 95-103. [CrossRef]

12. Bauer, F.; Hass, W. A New Approach to Analyze the Hydrodynamic Flow in Sealing Aids-PTFE-Lip Seals with Spiral Grooves. Tribol. Trans. 2007, 50, 435-443. [CrossRef]

13. Mach, J.-N.; Drechsler, S.; Bartel, D.; Poll, G.; Albers, A. Characterization of the Influence of the Topography on the Friction and Wear Behaviour of Tribo-Contacts in a CVT Transmission (in German: Charakterisierung des Einflusses der Topographie auf das Reibwert und Verschleißverhalten von Reibkontakten am Beispiel eines CVT-Getriebes). Tribol. Schmier. 2014, 61, 21-27.

14. Huang, W.; Jiang, L.; Zhou, C.; Wang, X. The Lubricant Retaining Effect of Micro-Dimples on the Sliding Surface of PDMS. Tribol. Int. 2012, 52, 87-93. [CrossRef]

15. Sinanoglu, C.; Nair, F.; Göksen, E. Effect of Micro and Macro Pits of Journal Surface on Radial Pressure Distribution of Journal Bearing. Indian J. Eng. Mater. Sci. 2008, 15, 300-310.

16. Suh, M.S.; Chae, Y.H.; Kim, S.S.; Hinoki, T.; Kohyama, A. Effect of Geometrical Parameters in Micro-Grooved Crosshatch Pattern under Lubricated Sliding Friction. Tribol. Int. 2010, 43, 1508-1517. [CrossRef]

17. Cho, M.H.; Park, S. Micro CNC Surface Texturing on Polyoxymethylene (POM) and its Tribological Performance in Lubricated Sliding. Tribol. Int. 2011, 44, 859-867. [CrossRef]

18. Meng, F.; Zhou, R.; Davis, T.; Cao, J.; Wang, Q.J.; Hua, D.; Liu, J. Study on Effect of Dimples on Friction of Parallel Surfaces under Different Sliding Conditions. Appl. Surf. Sci. 2010, 256, 2863-2875. [CrossRef]

19. Wakuda, M.; Yamauchi, Y.; Kanzaki, S.; Yasuda, Y. Effect of Surface Texturing on Friction Reduction Between Ceramic and Steel Materials Under Lubricated Sliding Contact. Wear 2003, 254, 356-363. [CrossRef]

20. Hadinata, P.A.; Stephens, L.S. Soft Elastohydrodynamic Analysis of Radial Lip Seals with Deterministic Microasperities on the Shaft. J. Tribol. 2007, 129, 851-859. [CrossRef]

21. Biboulet, N.; Bouassida, H.; Lubrecht, A.A. Cross Hatched Texture Influence on the Load Carrying Capacity of Oil Control Rings. Tribol. Int. 2015, 82A, 12-19. [CrossRef]

22. Lu, Y.; Liu, Y.; Wang, J.; Liu, H. Experimental Investigation into Friction Performance of Dimples Journal Bearing with Phyllotactic Pattern. Tribol. Lett. 2014, 55, 271-278. [CrossRef]

23. Ramesh, A.; Akram, W.; Mishra, S.P.; Cannon, A.H.; Polycarpou, A.A.; King, W.P. Friction Characteristics of Micro Textured Surfaces under Mixed and Hydrodynamic Lubrication. Tribol. Int. 2013, 57, 170-176. [CrossRef]

24. Checo, H.M.; Ausas, R.F.; Jai, M.; Cadalen, J.-P.; Choukroun, F.; Buscaglia, G.C. Moving Textures-Simulation of a Ring Sliding on a Textured Liner. Tribol. Int. 2014, 72, 131-142. [CrossRef] 
25. Wang, X.; Liu, W.; Zhou, F.; Zhu, D. Preliminary Investigation of the Effect of Dimple Size on Friction in Line Contacts. Tribol. Int. 2009, 42, 1118-1123. [CrossRef]

26. Korpela, T.; Suvanto, M.; Pakkanen, T.T. Friction and Wear of Periodically Micro-Patterned Polypropylene in Dry Sliding. Wear 2012, 289, 1-8. [CrossRef]

27. Galda, L.; Pawlus, P.; Sep, J. Dimples Shape and Distribution Effect on Characteristics of Stribeck Curve. Tribol. Int. 2009, 42, 1505-1512. [CrossRef]

28. Vladescu, S.-C.; Olver, A.V.; Pegg, I.G.; Reddyhoff, T. The Effects of Surface Texture in Reciprocating Contacts-An Experimental Study. Tribol. Int. 2015, 82A, 28-42. [CrossRef]

29. Voyer, J.; Klien, S.; Ausserer, F.; Velkavrh, I.; Ristow, A.; Diem, A. Friction Reduction Through Sub-Micro Laser Surface Modifications. Tribol. Schmier. 2015, 62, 13-18.

30. Voyer, J.; Ausserer, F.; Klien, S.; Ristow, A.; Velkavrh, I.; Diem, A.; Zehetner, J.; Stroj, S.; Heidegger, S.; Bertschler, C.; et al. Sub-Micro Laser Modifications of Tribological Surfaces. Mater. Perform. Charact. 2017, 6, 42-67. [CrossRef]

31. Gachot, C.; Rosenkranz, A.; Hsu, S.M.; Costa, H.L. A Critical Assessment of Surface Texturing for Friction and Wear Improvement. Wear 2017, 372-373, 21-41. [CrossRef]

32. Wacker Chemie AG-Technical Data Sheet for ELASTOSIL LR3022/60 (LSR). Available online: http://sdb.wacker.com/pf/e/result/main_fs1.jsp?P_SYS=2\&P_SSN=8888\&C001=TDS\&C002=*\&C003= *\&C012=000000000060084026\&ProductID=13604\&P_LANGU=E (accessed on 25 September 2017).

33. Persson, B.N.J. On the theory of rubber friction. Surf. Sci. 1998, 401, 445-454. [CrossRef]

34. Grosch, K.A. The Relation between the Friction and Visco-Elastic Properties of Rubber. Proc. R. Soc. Lond. A 1963, 274, 21-39. [CrossRef]

35. Mori, K.; Kaneda, S.; Kanae, K.; Hirahara, H.; Oishi, Y.; Iwabuchi, A. Influence on Friction Force of Adhesion Force between Vulcanizates and Sliders. Rubber Chem. Technol. 1994, 67, 797-805. [CrossRef]

36. Rudawska, A. Adhesive Properties of Metals and Metal Alloys. In Surface Energy; Aliofkhazraei, M., Ed.; InTech: Rijeka, Croatia, 2015; pp. 85-121, ISBN 978-953-512-216-6.

37. Erhard, G. The Friction and Wear Behavior of Polymer Materials (In German: Zum Reibungs-und Verschleißverhalten von Polymerwerkstoffen). Ph.D. Thesis, Karlsruhe University, Karlsruhe, Germany, 1980.

(C) 2017 by the authors. Licensee MDPI, Basel, Switzerland. This article is an open access article distributed under the terms and conditions of the Creative Commons Attribution (CC BY) license (http:/ / creativecommons.org/licenses/by/4.0/). 